\title{
Prognostic Significance of Exercise Plasma Noradrenaline Levels for Cardiac Death in Patients With Mild Heart Failure
}

\author{
Toru Kinugawa, MD; Kazuhide Ogino, MD; Shuichi Osaki, MD; \\ Masahiko Kato, MD; Osamu Igawa, MD; Ichiro Hisatome, MD; \\ Masatoshi Fujita, MD*; Chiaki Shigemasa, MD
}

\begin{abstract}
The present study was designed to determine whether exercise plasma noradrenaline (NA) levels could predict cardiac death in patients with mild heart failure in whom the plasma NA levels were only minimally elevated. Treadmill exercise testing with serial measurement of plasma NA and plasma adrenaline were performed in 142 patients with heart failure (New York Heart Association class I-II; age, 58 \pm 12 years) and 26 age-matched normal subjects. During a median follow-up of 9.6 years, 27 cardiac deaths occurred among the patients. By univariate Cox proportional hazard analysis, left ventricular end-systolic dimension $(\mathrm{p}<0.001)$, age $(\mathrm{p}<0.01)$, peak exercise heart rate $(\mathrm{p}<0.01)$, exercise plasma NA level $(\mathrm{p}<0.01)$ and left ventricular ejection fraction $(\mathrm{p}<0.001)$ were identified as significant prognostic markers. In a multivariate analysis, exercise plasma NA level was identified as the most powerful prognostic marker $(\mathrm{p}<0.001)$, followed by left ventricular end-systolic dimension and peak exercise heart rate. In addition, from the Kaplan-Meier analysis, patients with a supramedian level of exercise plasma NA concentration (NA $\geq 840 \mathrm{pg} / \mathrm{ml}$ ) had a significantly lower survival rate than those with an inframedian level $(\mathrm{p}<0.01)$. Exercise plasma NA levels can provide prognostic information in patients with mild heart failure, which suggests an important role of exercise-induced activation of sympathetic nervous system activity in the prognosis of patients with mild heart failure. (Circ J 2002; 66: 261-266)
\end{abstract}

Key Words: Exercise test; Heart failure; Plasma norepinephrine; Prognosis; Sympathetic nervous activity

$\mathbf{S}$ everal clinical and laboratory abnormalities are associated with the low survival rate of patients with chronic heart failure: (1) cardiac pump dysfunction expressed by left ventricular ejection fraction (LVEF); ${ }^{1-5}$ (2) New York Heart Association (NYHA) functional class; 6 (3) exercise performance; ;,7-9 and (4) the etiology of the heart disease 6,10 The degree of neurohormonal activation has also been implicated as an important prognostic factor and of the various neurohormonal factors, plasma noradrenaline (NA) levels are of particular importance in patients with heart failure. Cohn et al showed that an increased resting plasma NA concentration was related to high mortality in moderate to severe heart failure, ${ }^{11}$ and data from the Cooperative North Scandinavian Enalapril Survival Study (CONSENSUS) ${ }^{12}$ and the Vasodilator-Heart Failure Trial II (V-HeFT II) ${ }^{13}$ confirmed the prognostic significance of high resting plasma NA levels in a larger patient cohort with moderate to severe heart failure.

In patients with mild heart failure, on the other hand, resting plasma NA levels are not markedly elevated ${ }^{14}$ and so their significance for prognosis may be limited. Plasma NA level was a predictor of mortality in the Studies of Left

(Received October 31, 2001; revised manuscript received December 7, 2001; accepted December 20, 2001)

The Division of Cardiology, The 1st Department of Internal Medicine, Tottori University Faculty of Medicine, Yonago and *College of Medical Technology, Kyoto University, Kyoto, Japan

Mailing address: Toru Kinugawa, MD, Division of Cardiology, The 1st Department of Internal Medicine, Tottori University Faculty of Medicine, Yonago 683-8504, Japan. E-mail: kinugawa@grape.med. tottori-u.ac.jp
Ventricular Dysfunction (SOLVD) Trial, 15 but was not a prognostic factor in the Survival and Ventricular Enlargement (SAVE) Trial. ${ }^{16}$ We have previously demonstrated that the response of plasma NA level to exercise is augmented in patients with mild heart failure ${ }^{17}$ and it may be that the exercise plasma NA level provides more accurate prognostic information in these patients. However, the prognostic significance of the exercise plasma NA concentrations have not been well defined. Therefore, we conducted this study to determine whether exercise plasma NA levels can provide prognostic information in patients with mild heart failure.

\section{Methods}

Subjects

We enrolled 142 patients with heart failure (92 men, 50 women, age [mean $\pm \mathrm{SD}$ ]: $58.1 \pm 11.5$ years, NYHA class I-II), and 26 age-matched normal subjects (15 men, 11 women, age [mean \pm SD]: $54.8 \pm 7.0$ years) who did not have cardiovascular disease. The etiology of the heart failure included old myocardial infarction in 71 , valvular heart disease in 57, dilated cardiomyopathy in 9, and others in 5. The presence of coronary artery disease was established by coronary angiography or a history of previously documented myocardial infarction. Patients with valvular heart disease had regurgitant valvular lesions with either mitral regurgitation, aortic regurgitation, or both. Patients with effort angina, unstable angina, significant aortic stenosis, or airway diseases were excluded. Thirty-six of 142 patients had chronic atrial fibrillation; the remainder were in normal 
Table 1 Baseline Characteristics of the Survivor and Cardiac Death Groups

\begin{tabular}{|c|c|c|}
\hline & $\begin{array}{l}\text { Survivor group } \\
\quad(n=92)\end{array}$ & $\begin{array}{c}\text { Cardiac death group } \\
(n=27)\end{array}$ \\
\hline \multicolumn{3}{|l|}{ Baseline characteristics } \\
\hline Age (years) & $55.3 \pm 1.1$ & $64.6 \pm 2.4 *$ \\
\hline Male sex: $n(\%)$ & $56(61 \%)$ & $20(74 \%)$ \\
\hline$B M I\left(k g / m^{2}\right)$ & $22.1 \pm 0.3$ & $22.3 \pm 0.5$ \\
\hline Smokers: $n(\%)$ & $45(49 \%)$ & $16(59 \%)$ \\
\hline$H T: n(\%)$ & $24(26 \%)$ & $11(41 \%) *$ \\
\hline$D M: n(\%)$ & $15(16 \%)$ & $6(22 \%)$ \\
\hline Atrial fibrillation: $n(\%)$ & $27(29 \%)$ & $2(7 \%) *$ \\
\hline \multicolumn{3}{|l|}{ Etiology of heart diseases } \\
\hline OMI: $n(\%)$ & $48(52 \%)$ & $13(56 \%)$ \\
\hline$D C M: n(\%)$ & $3(3 \%)$ & $6(22 \%) *$ \\
\hline$V H D: n(\%)$ & $38(40 \%)$ & $5(19 \%)$ \\
\hline Others: $n(\%)$ & $3(3 \%)$ & $1(3 \%)$ \\
\hline \multicolumn{3}{|l|}{ ECG and chest $X$-ray } \\
\hline$S V_{l}+R V_{5}$ in $E C G(m V)$ & $2.9 \pm 0.1$ & $2.9 \pm 0.3$ \\
\hline Cardio-thoracic ratio (\%) & $54.7 \pm 0.8$ & $56.7 \pm 1.3$ \\
\hline \multicolumn{3}{|l|}{ Echocardiographic parameters } \\
\hline $\operatorname{LVDd}(\mathrm{mm})$ & $51.2 \pm 0.9$ & $56.6 \pm 2.4$ \\
\hline LVDs $(\mathrm{mm})$ & $36.3 \pm 0.9$ & $44.2 \pm 2.8^{*}$ \\
\hline $\operatorname{LVEF}(\%)$ & $61.3 \pm 1.5$ & $52.2 \pm 3.1 *$ \\
\hline $\operatorname{IVSth}(\mathrm{mm})$ & $9.9 \pm 0.2$ & $9.7 \pm 0.3$ \\
\hline$P W t h(m m)$ & $10.2 \pm 0.2$ & $10.2 \pm 0.3$ \\
\hline \multicolumn{3}{|l|}{ Medications } \\
\hline Diuretics & $33(36 \%)$ & $12(48 \%)$ \\
\hline Digitalis & $34(37 \%)$ & $14(52 \%)$ \\
\hline Vasodilators & $49(52 \%)$ & $17(63 \%)$ \\
\hline$\beta$-blockers & $4(4 \%)$ & $2(7 \%)$ \\
\hline Antiarrhythmic agents & $8(9 \%)$ & $9(33 \%) *$ \\
\hline Antiplatelet agents & $33(36 \%)$ & $8(30 \%)$ \\
\hline Warfarin & $9(10 \%)$ & $4(15 \%)$ \\
\hline
\end{tabular}

BMI, body mass index; HT, hypertension; DM, diabetes mellitus; OMI, old myocardial infarction; DCM, dilated cardiomyopathy; $V H D$, valvular heart disease; LVDd, left ventricular end-diastolic dimension; LVDs, left ventricular end-systolic dimension; LVEF, left ventricular ejection fraction; IVSth, interventricular septal thickness; PWth, posterior wall thickness. Values are mean \pm SEM. $*_{p}<0.05$ vs survivor group.

sinus rhythm. At the time of the entry, patients were being treated with diuretics $(39 \%)$, digitalis $(40 \%), \beta$-blockers $(4 \%)$, antiarrhythmic agents $(13 \%)$, antiplatelet agents $(34 \%)$, warfarin $(11 \%)$, and vasodilators $(55 \%)$ such as angiotensin-converting enzyme inhibitors, long-acting nitrates, and calcium channel antagonists. The protocol was approved by the Ethics Committee of Tottori University and all subjects gave their informed consent to participate in the study.

\section{Exercise Testing}

A multistage treadmill exercise test was performed (CASE II, Marquette Electronics Co Milwaukee, WI, USA) using either the modified Bruce or the Sheffield protocol as previously described ${ }^{17}$ The criteria for terminating exercise were (i) achievement of $85 \%$ of age-adjusted predicted maximal heart rate; (ii) leg fatigue or shortness of breath; (iii) significant ST segment depression $(\geq 0.2 \mathrm{mV})$; (iv) frequent premature ventricular contractions; (v) abnormal blood pressure response; or (vi) finishing stage $\mathrm{V}$ of the modified Bruce protocol (exercise time $=15 \mathrm{~min}$ ). The number of metabolic equivalents (METs) achieved was estimated from the treadmill speed and grade based on previously reported findings 18

\section{Plasma Catecholamine Measurements}

Blood samples for measurements of plasma NA and plasma adrenaline levels were obtained after $30 \mathrm{~min}$ of rest in the supine position, immediately after exercise and $5 \mathrm{~min}$ postexercise. Plasma NA and adrenaline concentrations were determined by high-performance liquid chromatography combined with the trihydroxyindole fluorometric procedure, as previously described! ${ }^{17}$

\section{Baseline Data}

Body mass index was calculated as body weight in kilograms divided by height in meters squared. A 12-lead ECG was obtained and $\mathrm{SV}_{1}+\mathrm{RV}_{5}$ (in $\mathrm{mV}$ ) was calculated. The cardiothoracic ratio was calculated from chest X-ray. During the echocardiographic study, the left ventricular volume was calculated using the Teichholz modification, ${ }^{19}$ and the LVEF was calculated as [(end-diastolic volumeend-systolic volume)/end-diastolic volume] $\times 100$.

\section{Endpoint}

Follow-up data were obtained from routine hospital visits, a telephone interview with the patient or family members, and a questionnaire sent to the patients. The endpoint of the study was cardiac death, which included heart failure death and sudden death. Cardiac deaths within $24 \mathrm{~h}$ of acute symptoms heralded by an abrupt loss of consciousness were considered 'sudden', whereas those resulting from deterioration of congestive symptoms were classified as 'progressive heart failure'. For patients who died during the follow-up period, additional information was obtained from the attending physicians, hospital charts, or by phone contact of the patient's relatives. All events were determined by reviewers who were blind to the 
results of exercise testing.

\section{Statistical Analysis}

Data are presented as the mean \pm SEM for continuous variables and as percentage for categorical variables. Differences between the 2 groups (survivor group and cardiac death group) were tested for significance by MannWhiteny U test. The chi-square test was used for comparing categorical variables. Repeated measures analysis of variance (ANOVA) was used to examine the difference in heart rate, systolic blood pressure, and plasma NA and adrenaline response to exercise. To determine the independent predictors for cardiac death, univariate and multivariate analyses were performed using the Cox proportionalhazards regression model. Survival curves were traced using the Kaplan-Meier method and compared using a logrank test. All analyses were performed with a StatView statistical program (Version 5.0, SAS Institute Inc Cary, NC, USA). The differences were considered significant when $\mathrm{p}$ values were less than 0.05 .

\section{Results}

\section{Follow-up Data}

During a median follow-up period of 9.6 years (range, 0.5-12.2 years), 27 cardiac deaths (15 progressive heart failure deaths and 12 sudden deaths) and 23 non-cardiac deaths (6 stroke deaths, 5 cancer deaths, and 12 deaths from other reasons) occurred among the 142 patients with heart failure. No cardiac deaths occurred among the 26 normal subjects. Because the endpoint of the present study was cardiac death, we excluded subjects with non-cardiac death from further analysis. Therefore, the final study population consisted of 119 patients with heart failure and 26 normal subjects.

\section{Baseline Characteristics and Exercise Tolerance}

Compared with the survivors, patients in the cardiac death group were older (Table 1) and the group included more patients with hypertension and dilated cardiomyopathy. In the patients who died, the left ventricular endsystolic dimension was larger and the LVEF was lower. Drug regimens at the time of the entry were similar between the 2 groups, except for the more frequent use of antiarrhythmic agents in patients who eventually died of cardiac death. No difference was detectable between the 2 groups in the male to female ratio, body mass index, number of smokers, coexisting diabetes mellitus, or degree of left ventricular hypertrophy. The serum creatinine level, lipid profiles, and liver function were not significantly different between the 2 groups (data not shown).
There was no significant difference in exercise tolerance between the 2 groups (survivors vs cardiac death: $7.1 \pm 0.3$ vs $6.2 \pm 0.5$ METs, NS). The reasons for exercise termination were symptoms (46\% vs $48 \%$ ), achievement of target heart rate $(36 \%$ vs $37 \%)$, ECG abnormalities (13\% vs $11 \%)$, and others ( $2 \%$ vs $4 \%)$, and these values did not differ significantly between the 2 groups.

\section{Heart Rate, Blood Pressure, and Plasma NA Response to Exercise}

The response of heart rate, systolic blood pressure, and plasma catecholamine to exercise are shown in Fig 1. The peak exercise heart rate $(135 \pm 2$ vs $117 \pm 5$ beats $/ \mathrm{min}, \mathrm{p}<0.01)$ was significantly lower in the cardiac death group, as was the peak systolic blood pressure $(168 \pm 4$ vs $155 \pm 6 \mathrm{mmHg}$, $\mathrm{p}<0.01)$. The plasma NA levels at rest were not significantly different between the 2 groups $(195 \pm 12$ vs $217 \pm 18 \mathrm{pg} / \mathrm{ml}$, NS), but those at peak exercise $(894 \pm 51$ vs $1,203 \pm 183$ $\mathrm{pg} / \mathrm{ml}, \mathrm{p}<0.01)$, and $5 \mathrm{~min}$ postexercise $(334 \pm 22$ vs $493 \pm 104$ $\mathrm{pg} / \mathrm{ml}, \mathrm{p}<0.01)$ were significantly higher in patients in the cardiac death group. The plasma adrenaline response to exercise was not significantly different between the 2 groups (ANOVA, $\mathrm{p}=0.18$ ).
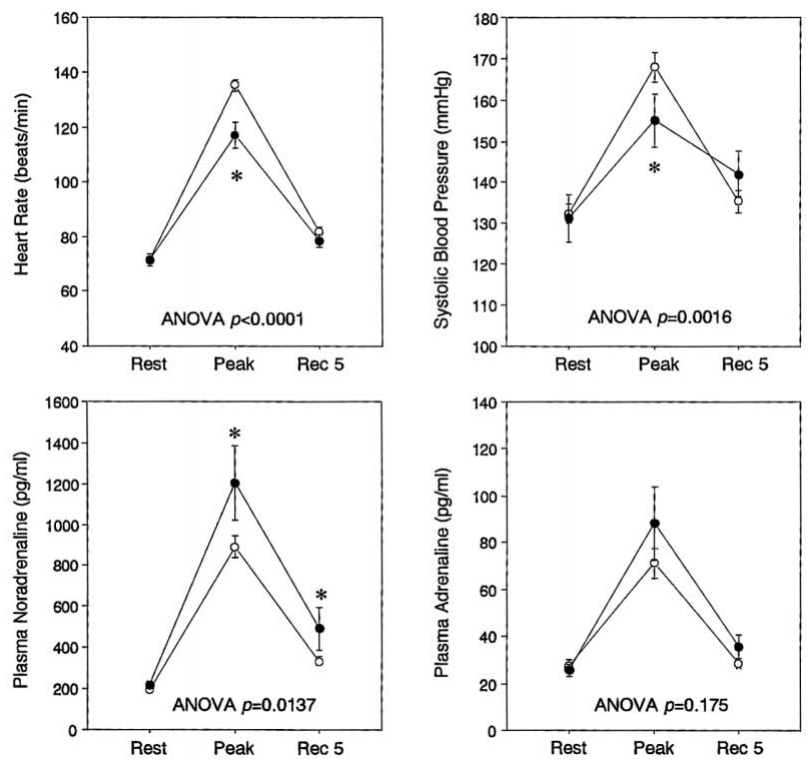

Fig 1. Serial changes in heart rate, systolic blood pressure and plasma noradrenaline and adrenaline levels in response to exercise in patients in the cardiac death group (closed circles) and survivors (open circles). Peak, peak exercise; Rec 5, 5 min postexercise. Values are mean \pm SEM. *p $<0.05$ vs survivors.

Table 2 Univariate and Multivariate Predictors of Cardiac Death in Patients With Mild Heart Failure

\begin{tabular}{|c|c|c|c|c|}
\hline \multirow{2}{*}{ Variable } & \multicolumn{2}{|c|}{ Univariate } & \multicolumn{2}{|c|}{ Multivariate } \\
\hline & chi-square & $p$ value & chi-square & $p$ value \\
\hline LV end-systolic dimension & 14.54 & 0.0001 & 18.27 & $<0.0001$ \\
\hline Age & 13.65 & 0.0019 & 2.15 & 0.4705 \\
\hline Peak exercise $H R$ & 13.37 & 0.0003 & 13.97 & 0.0002 \\
\hline Exercise plasma NA level & 8.71 & 0.0032 & 21.13 & $<0.0001$ \\
\hline LV ejection fraction & 8.58 & 0.0002 & 0.82 & 0.5166 \\
\hline Peak exercise SBP & 3.04 & 0.0813 & 0.91 & 0.3388 \\
\hline Resting plasma NA level & 1.23 & 0.2662 & 0.64 & 0.4205 \\
\hline
\end{tabular}

$L V$, left ventricular; HR, heart rate; NA, noradrenaline; SBP, systolic blood pressure. 


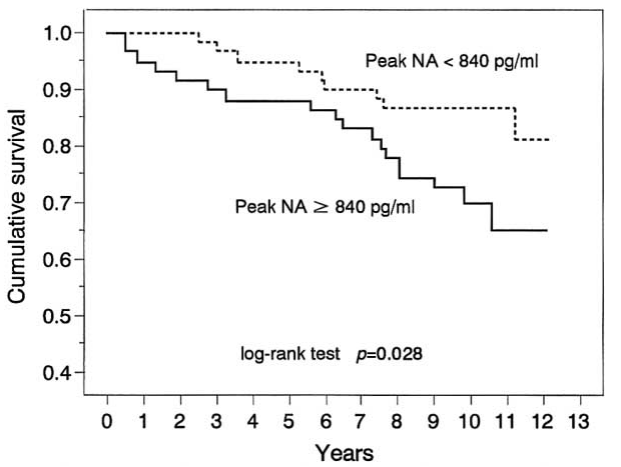

Fig 2. Kaplan-Meier analysis of the cumulative rates of survival in patients with heart failure stratified into 2 groups on the basis of a median concentration $(840 \mathrm{pg} / \mathrm{ml})$ of peak exercise plasma noradrenaline (NA). The prognosis of patients with peak exercise plasma NA levels $\geq 840 \mathrm{pg} / \mathrm{ml}$ differed significantly from those with lower peak exercise plasma NA levels $(<840 \mathrm{pg} / \mathrm{ml})$.

In the 26 normal subjects, resting and peak exercise heart rates were $65 \pm 2$ and $142 \pm 2$ beats/min, respectively. The peak exercise heart rate in patients in the cardiac death group was significantly lower than that of normal subjects. In normal subjects, the resting and peak exercise plasma NA levels were $137 \pm 10$ and $677 \pm 91 \mathrm{pg} / \mathrm{ml}$, respectively. The resting plasma NA concentration in both survivors $(195 \pm 12 \mathrm{pg} / \mathrm{ml})$ and those who died from cardiac death $(217 \pm 18 \mathrm{pg} / \mathrm{ml})$ was slightly, but significantly higher than that of normal subjects. The peak exercise plasma NA level in patients in the cardiac death group $(1,203 \pm 183 \mathrm{pg} / \mathrm{ml})$ was significantly higher than that of normal subjects.

\section{Prognostic Analysis and Kaplan-Meier Survival Curve}

To detect independent predictors for cardiac death, the following 7 variables were analyzed using Cox regression analyses: (1) age; (2) LVEF; (3) left ventricular end-systolic dimension; (4) peak exercise heart rate; (5) peak exercise systolic blood pressure; (6) resting plasma NA level; and (7) peak exercise plasma NA level (Table 2). By univariate analysis, left ventricular end-systolic dimension, age, peak exercise heart rate, exercise plasma NA level, and LVEF were significant predictors for cardiac death. According to stepwise multivariate analyses, exercise plasma NA level, left ventricular end-systolic dimension, and peak exercise heart rate were significant predictors and of these exercise plasma NA level was identified as the most powerful prognostic marker. Kaplan-Meier survival curves were plotted for the 2 groups of patients on the basis of a median concentration $(840 \mathrm{pg} / \mathrm{ml})$ of exercise plasma NA (Fig 2). Survival rate was significantly lower in patients with peak exercise plasma NA level $\geq 840 \mathrm{pg} / \mathrm{ml}$ than for those with an exercise plasma NA level below this cut-off point (logrank $\mathrm{p}=0.028$ ).

\section{Discussion}

The novel finding in this study was that in patients with mild heart failure, whose resting plasma NA levels is only mildly elevated, exercise plasma NA concentrations can provide prognostic information for cardiac death.

\section{Exercise Plasma NA Level as a Prognostic Factor}

Compared with the age-matched normal subjects, the patients with mild heart failure had slightly higher plasma NA levels, which was consistent with previous reports! ${ }^{14-16}$ When the resting plasma NA levels were compared between the cardiac death patients and the survivors, no significant differences were found. However, the peak plasma NA levels immediately after exercise were significantly higher in patients in the cardiac death group compared with survivors. Multivariate analysis revealed that exercise plasma NA level was the most powerful prognostic marker for cardiac mortality. Furthermore, patients with an exercise plasma NA concentration equal to or above a median level (NA $\geq 840 \mathrm{pg} / \mathrm{ml}$ ) had a significantly worse prognosis than those with a lower exercise plasma NA levels. Therefore, the exercise plasma NA level can provide important prognostic information for cardiac mortality in patients with mild heart failure.

To our knowledge, only one earlier study has investigated the prognostic value of the plasma NA level during exercise 20 but that study did not find it to be of prognostic value. There are important differences between the 2 studies. First, Madsen et al included patients with more advanced heart failure and lower mean LVEF. Second, their patients were older than the present patients. Third, they used an upright ergometer exercise test, whereas we used a treadmill exercise test. These differences may explain, at least in part, the inconsistent results.

\section{Left Ventricular End-Systolic Dimension and Chronotropic Incompetence as Prognostic Factors}

Our study confirmed previously reported findings that the left ventricular end-systolic dimension is a significant prognostic marker for cardiac death21 Many previous studies have demonstrated that the LVEF is a strong prognostic marker for mortality in patients with heart failure, ${ }^{1-5}$ but although univariate analysis in the present study confirmed the relationship between LVEF and cardiac mortality, LVEF did not provide additional prognostic information after the introduction of peak exercise plasma NA levels and left ventricular end-systolic dimension as covariates in the multivariate model. We speculate that the relatively well-preserved systolic function in the present patients made the prognostic value of the LVEF inferior compared with the other variables.

In the patients in the cardiac death group, the increase in heart rate during exercise was blunted despite the exaggerated activation of sympathetic nervous system activity, and the smaller peak in heart rate was a prognostic marker. These results are consistent with recent reports that demonstrated chronotropic incompetence is an important prognostic marker22,23 Although the precise mechanism has not been clarified, abnormalities in the $\beta$-adrenergic receptor pathway may be involved 4

\section{Clinical Implications}

Neurohormonal activation with increased plasma levels of noradrenaline, natriuretic peptides, endothelin-1, and angiotensin II is a hallmark of congestive heart failure and recent reports have emphasized the importance of plasma brain natriuretic peptide ${ }^{25}$ and endothelin- ${ }^{26}$ concentrations. However, the value of exercise neurohormones in predicting morbidity and mortality is relatively unknown.

A high plasma NA level in moderate to severe heart failure is an important prognostic marker, but its prognostic value for patients with mild heart failure is limited. Dynamic exercise increases the plasma NA level and a subgroup of 
patients exhibits an exaggerated response to exercise. Our data suggest that such patients are at high risk for cardiac death, and this test can be used as a prognostic marker for mild heart failure patients in whom resting plasma NA levels are only minimally elevated.

An excessive increase in sympathetic nervous system activity appears to be deleterious for patients with heart failure. Although the direct association between augmented plasma NA during exercise and increased cardiac mortality is not clear, the persistent exposure to high plasma NA levels at the time of exercise stress may be harmful in patients who already have organic heart disease. A growing body of evidence indicates that $\beta$-blockers improve prognosis in patients with heart failure ${ }^{27}$ but because the present study began in late 1980, many of the patients were not on this treatment. We speculate that drug regimens with $\beta$ blockers would lead to a better prognosis in those patients with heart failure who show the augmented plasma NA response during exercise, although it was not within the scope of our current investigation.

\section{Study Limitations}

We acknowledge that there are several limitations to this study. First, because of the inclusion of patients with valvular heart disease, the mean LVEF was relatively high and thus, our conclusions cannot readily be extended to those with a depressed LVEF. Second, we did not measure oxygen uptake and blood lactate levels and the exercise workload of the heart failure patients could be more precisely evaluated with these measurements. Third, the reproducibility of exercise plasma NA levels was not determined. Fourth, we did not assess the effects of various medications and exercise and these factors may have influenced the prognosis ${ }^{28,29}$ Finally, there is a limitation in using plasma NA level as an index of sympathetic nervous system activity, because plasma NA concentration is regulated by multiple factors $3^{30}$ However, a good correlation between muscle sympathetic nerve activity and plasma NA level has been reported in patients with heart failure, 31 suggesting the clinical usefulness of the plasma NA level as an overall sympathetic outflow.

\section{Conclusions}

The present study showed that the exercise plasma NA level can provide prognostic information in patients with mild heart failure in whom the resting plasma NA levels are minimally elevated. These results suggest an important role of exercise-induced activation of sympathetic nervous system activity in the prognosis of patients with mild heart failure.

\section{References}

1. Cohn JN, Archibald DG, Ziesche S, Ranciosa JA, Harston WE, Tristani FE, et al. Effects of vasodilator therapy on mortality in chronic congestive heart failure: Results of a Veterans Administration Cooperative Study. N Engl J Med 1986; 314: 1547-1552.

2. Schwarz F, Mall G, Zebe H, Schmitzer E, Manthey J, Scherlen H, et al. Determinants of survival in patients with congestive cardiomyopathy: Quantitative morphologic findings and left ventricular hemodynamics. Circulation 1984; 70: 923-928.

3. Cohn JN, Johnson GR, Shabetai R, Loeb H, Tristani F, Rector T, et al for the V-HeFT VA Cooperative Studies Group. Ejection fraction, peak exercise oxygen consumption, cardiothoracic ratio, ventricular arrhythmias, and plasma norepinephrine as determinants of prognosis in heart failure. Circulation 1993; 87(Suppl VI): VI-5-VI-16.

4. Bittner V, Weiner DH, Yusuf S, Rogers WJ, McIntyre KM,
Bangdiwala SI, et al for the SOLVD Investigators. Prediction of mortality and morbidity with a 6-min walk test in patients with left ventricular dysfunction. JAMA 1993; 270: 1702-1707.

5. Parameshwar J, Keegan J, Sparrow J, Sutton GC, Poole-Wilson PA. Predictors of prognosis in severe chronic heart failure. Am Heart $J$ 1992; 123: 421-426

6. Gradman A, Deedwania P, Cody R, Massie B, Packer M, Pitt B, et al for the Captopril-Digoxin Study Group. Predictors of total mortality and sudden death in mild to moderate heart failure. $\mathrm{J} \mathrm{Am}$ Coll Cardiol 1989; 14: 564-570.

7. Meyers J, Gullestad L, Vagelos R, Do D, Bellin D, Ross H, et al. Clinical, hemodynamic, and cardiopulmonary exercise test determinants of survival in patients referred for evaluation of heart failure. Ann Intern Med 1998; 129: 286-293.

8. Osada N, Chaitman BR, Miller LW, Yip D, Cishek MB, Wolford TL, et al. Cardiopulmonary exercise testing identifies low risk patients with heart failure and severely impaired exercise capacity considered for heart transplantation. J Am Coll Cardiol 1998; 31: 577-582.

9. Hulsmann M, Stanek B, Frey B, Sturm B, Putz D, Kos T, et al. Value of cardiopulmonary exercise testing and big endothelin plasma levels to predict short-term prognosis of patients with chronic heart failure. J Am Coll Cardiol 1998; 32: 1695-1700.

10. Bart BA, Shaw LK, McCants CB Jr, Fortin DF, Lee KL, Califf RM, et al. Clinical determinants of mortality in patients with angiographically diagnosed ischemic or nonischemic cardiomyopathy. J Am Coll Cardiol 1997; 30: $1002-1008$.

11. Cohn JN, Levine TB, Olivari MT, Garberg V, Lura D, Francis GS, et al. Plasma norepinephrine as a guide to prognosis in patients with chronic congestive heart failure. N Engl J Med 1984; 311: 819-823.

12. Swedberg K, Eneroth P, Kjekshus J, Wilhelmsen L, for the CONSENSUS Trial Study Group. Hormones regulating cardiovascular function in patients with severe congestive heart failure and their relation to mortality. Circulation 1990; 82: 1730-1736.

13. Francis GS, Cohn JN, Johnson G, Rector TS, Goldman S, Simon A, for the V-HeFT VA Cooperative Studies Group. Plasma norepinephrine, plasma renin activity, and congestive heart failure: Relationship to survival and the effects of therapy in V-HeFT II. Circulation 1993; 87(Suppl VI): VI-40 - VI-48.

14. Francis GS, Benedict C, Johnstone DE, Kirlin PC, Nicklas J, Liang $\mathrm{C}-\mathrm{S}$, et al for the SOLVD Investigators. Comparison of neuroendocrine activation in patients with left ventricular dysfunction with and without congestive heart failure: A substudy of the Studies of Left Ventricular Dysfunction (SOLVD). Circulation 1990; 82: 17241729.

15. Benedict CR, Shelton B, Johnstone DE, Francis G, Greenberg B, Konstman M, et al for the SOLVD investigators. Prognostic significance of plasma norepinephrine in patients with asymptomatic left ventricular dysfunction. Circulation 1996; 94: 690-697.

16. Rouleau J-L, Packer M, Moye L, de Champlain J, Bichet D, Klein M, et al. Prognostic value of neurohumoral activation in patients with an acute myocardial infarction: Effect of captopril. J Am Coll Cardiol 1994; 24: 583-591.

17. Kinugawa T, Ogino K, Kitamura H, Miyakoda H, Saitoh M, Hasegawa J, et al. Response of sympathetic nervous system activity to exercise in patients with congestive heart failure. Eur J Clin Invest 1991; 21: $542-547$.

18. Sotohata I, Shino T, Kondo T, Tsuzuki J. Work intensities of different modes of exercise testing in clinical use. Jpn Circ J 1979; 43: $161-169$.

19. Teichholz LE, Kreulen T, Herman MV, Gorlin R: Problems in echocardiographic volume determinations: Echocardiographicangiographic correlations in the presence or absence of asynergy. Am J Cardiol 1976; 37: 7-11.

20. Madsen BK, Keller N, Christiansen E, Christensen NJ. Prognostic value of plasma catecholamines, plasma renin activity, and plasma atrial natriuretic peptide at rest and during exercise in congestive heart failure: Comparison with clinical evaluation, ejection fraction, and exercise capacity. J Card Fail 1995; 1: 207-216.

21. White H, Norris RM, Brown MA, Brandt PW, Whitlock RML, Wild CJ. Left ventricular volume as the major determinant of survival after recovery from myocardial infarction. Circulation 1987; 76: 44-51.

22. Lauer MS, Francis GS, Okin PM, Pashkow FJ, Snader CL, Marwick TH. Impaired chronotropic response to exercise stress testing as a predictor of mortality. JAMA 1999; 281: 524-529.

23. Sandvik L, Erikssen J, Ellestad M, Erikssen G, Thaulow E, Mundal $\mathrm{R}$, et al. Heart rate increase and maximal heart rate during exercise as predictors of cardiovascular mortality: A 16-year follow-up study of 1960 healthy men. Coron Artery Dis 1995; 6: 667-678.

24. Colucci WS, Ribeiro JP, Rocco MB, Quigg RJ, Creager MA, Marsh $\mathrm{JD}$, et al. Impaired chronotropic response to exercise in patients with 
congestive heart failure: Role of postsynaptic $\beta$-adrenergic desensitization. Circulation 1989; 80: 314-323.

25. Tsutamoto T, Wada A, Maeda K, Hisanaga T, Naeda Y, Fukai D, et al. Attenuation of compensation of endogenous cardiac natriuretic peptide system in chronic heart failure: Prognostic role of plasma brain natriuretic peptide concentration in patients with chronic symptomatic left ventricular dysfunction. Circulation 1997; 96: 509-516.

26. Monge JC. Neurohormonal markers of clinical outcome in cardiovascular disease: Is endothelin the best one? J Cardiovasc Pharmacol 1998; 32(Suppl 2): S36-S42.

27. HFSA. Guidelines for management of patients with heart failure caused by left ventricular systolic dysfunction: Pharmacological approaches (Heart Failure Society of America). J Card Fail 1999; 5: 357-382.

28. Inoko M, Fujita M, Nakae I, Tamaki S, Watanuki M, Hashimoto T, et al. Effect of angiotensin-converting enzyme inhibitor on sympathetic tone in patients with mild to moderate heart failure. Jpn Circ J 2001; 65: 395-398.

29. Takeyama J, Itoh H, Kato M, Koike A, Aoki K, Fu LT, et al. Effects of physical training on the recovery of the autonomic nervous activity during exercise after coronary artery bypass grafting: Effects of physical training after CABG. Jpn Circ J 2000; 64: 809-813.

30. Esler M, Jennings G, Korner P, Willett I, Dudley F, Hasking G, et al. Assessment of human sympathetic nervous system activity from measurements of norepinephrine turnover. Hypertension 1988; 11: $3-20$.

31. Leimbach WM, Wallin BG, Victor RG, Aylward PE, Sundlof G, Mark AL. Direct evidence from intraneural recordings for increased central sympathetic outflow in patients with heart failure. Circulation 1986; 73: $913-919$. 